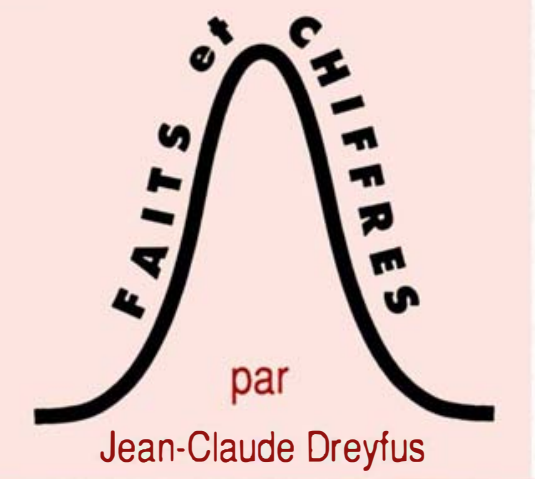

\title{
Actualité démographique européenne
}

\begin{tabular}{|c|c|c|c|c|c|c|c|c|c|c|c|}
\hline & \multirow{3}{*}{$\begin{array}{c}\begin{array}{c}\text { Population } \\
\text { moyenne } \\
\text { (milliers) }\end{array} \\
1989\end{array}$} & \multirow{3}{*}{$\begin{array}{c}\begin{array}{c}\text { Naissances } \\
\text { (milliers) }\end{array} \\
1989\end{array}$} & \multirow{3}{*}{$\begin{array}{c}\begin{array}{c}\text { Décès } \\
\text { (milliers) }\end{array} \\
1989\end{array}$} & \multicolumn{2}{|c|}{$\begin{array}{l}\text { Taux brut } \\
\text { (pour } 1000 \text { habitants) }\end{array}$} & \multirow{2}{*}{\multicolumn{2}{|c|}{$\begin{array}{l}\text { Indicateur conjoncturel } \\
\text { de fécondité } \\
\text { (nombre moyen } \\
\text { d'enfants par femme) }\end{array}$}} & \multirow{2}{*}{\multicolumn{2}{|c|}{$\begin{array}{l}\text { Taux de mortalité } \\
\text { infantile (pour } \\
1000 \text { naissances) }\end{array}$}} & \multirow{2}{*}{\multicolumn{2}{|c|}{$\begin{array}{c}\text { Vie moyenne } \\
\text { vers } 1987 \text { (en années) }\end{array}$}} \\
\hline & & & & \multirow{2}{*}{$\begin{array}{c}\text { natalité } \\
1989\end{array}$} & \multirow{2}{*}{$\begin{array}{l}\text { mortalité } \\
1989\end{array}$} & & & & & & \\
\hline & & & & & & 1988 & 1989 & 1988 & 1989 & $S M$ & SF \\
\hline $\begin{array}{l}\text { Europe du Nord } \\
\text { Danemark } \\
\text { Finlande } \\
\text { Irlande } \\
\text { Islande } \\
\text { Norvège } \\
\text { Royaume-Uni } \\
\text { Suède }\end{array}$ & $\begin{array}{r}5133 \\
4960 \\
3511 \\
250 \\
4228 \\
57243 \\
8493\end{array}$ & $\begin{array}{c}61,5 \\
63,3 \\
51,4 \\
4,7 \text { (a) } \\
59,2 \\
777,3 \\
115,9\end{array}$ & $\begin{array}{c}59,4 \\
49,0 \\
31,1 \\
1,8 \text { (a) } \\
45,0 \\
657,7 \\
92,1\end{array}$ & $\begin{array}{l}12,0 \\
12,8 \\
14,6 \\
18,7(a) \\
14,0 \\
13,6 \\
13,6\end{array}$ & $\begin{array}{l}11,6 \\
9,9 \\
8,9 \\
7,3 \text { (a) } \\
10,6 \\
11,5 \\
10,8\end{array}$ & $\begin{array}{l}1,56 \\
1,59 \\
2,17 \\
2,27 \\
1,84 \\
1,83 \\
1,96\end{array}$ & $\begin{array}{l}1,62 \\
2,11\end{array}$ & $\begin{array}{l}7,6 \\
5,4 \\
7,4 \\
6,2 \\
8,0 \\
9,0 \\
5,8\end{array}$ & 7,6 & $\begin{array}{l}71,8 \\
70,7 \\
71,0 \\
75,0 \\
72,8 \\
71,9 \\
74,2\end{array}$ & $\begin{array}{l}77,6 \\
78,7 \\
76,7 \\
80,1 \\
79,6 \\
77,6 \\
80,2\end{array}$ \\
\hline $\begin{array}{l}\text { Europe de l'Ouest } \\
\text { Allemagne (RFA) } \\
\text { Allemagne (RDA) } \\
\text { Autriche } \\
\text { Belgique } \\
\text { France } \\
\text { Luxembourg } \\
\text { Pays-Bas } \\
\text { Suisse }\end{array}$ & $\begin{array}{r}62200 \\
16555 \\
7631 \\
9938 \\
56161 \\
377 \\
14848 \\
6650\end{array}$ & $\begin{array}{c}681,5 \\
198,9 \\
88,8 \\
121,1 \\
765,0 \\
4,7 \\
189,0 \\
80,3 \text { (a) }\end{array}$ & $\begin{array}{c}692,7 \\
205,7 \\
83,4 \\
107,6 \\
528,0 \\
4,0 \\
128,9 \\
60,6 \text { (а) }\end{array}$ & $\begin{array}{l}11,0 \\
12,0 \\
11,6 \\
12,2 \\
13,6 \\
12,4 \\
12,7 \\
12,2 \text { (a) }\end{array}$ & $\begin{array}{r}11,1 \\
12,4 \\
10,9 \\
10,8 \\
9,4 \\
10,6 \\
8,7 \\
9,2 \text { (a) }\end{array}$ & $\begin{array}{l}1,40 \\
1,67 \\
1,44 \\
1,56 \\
1,82 \\
1,51 \\
1,54 \\
1,51 \text { (b) }\end{array}$ & $\begin{array}{l}1,39 \\
1,45 \\
1,58 \\
1,81 \\
1,52 \\
1,55\end{array}$ & $\begin{array}{l}7,5 \\
8,1 \\
8,1 \\
9,0 \\
7,8 \\
8,7 \\
6,8 \\
6,8\end{array}$ & $\begin{array}{l}7,5 \\
7,6 \\
8,3 \\
8,6 \\
7,5 \\
9,9\end{array}$ & $\begin{array}{l}71,5 \\
69,7 \\
71,5 \\
70,0(f) \\
72,0 \\
70,6 \\
73,5 \\
73,8\end{array}$ & $\begin{array}{l}78,1 \\
76,0 \\
78,1 \\
76,8(f) \\
80,3 \\
77,9 \\
80,1 \\
80,5\end{array}$ \\
\hline $\begin{array}{l}\text { Europe de l'Est } \\
\text { Bulgarie } \\
\text { Hongrie } \\
\text { Pologne } \\
\text { Roumanie } \\
\text { Tchécoslovaquie }\end{array}$ & $\begin{array}{r}9000 \\
10583 \\
37850 \\
23152 \\
15629\end{array}$ & $\begin{array}{l}116,7 \text { (b) } \\
120,6 \\
562,6 \\
369,5 \\
208,6\end{array}$ & $\begin{array}{l}107,2 \text { (b) } \\
140,9 \\
381,2 \\
247,3 \\
181,6\end{array}$ & $\begin{array}{l}13,0 \text { (b) } \\
11,4 \\
14,9 \\
16,0 \\
13,3\end{array}$ & $\begin{array}{l}12,0(b) \\
13,3 \\
10,1 \\
10,7 \\
11,6\end{array}$ & $\begin{array}{l}1,96 \text { (b) } \\
1,81 \\
2,15 \text { (b) } \\
2,31 \text { (d) } \\
2,02\end{array}$ & 1,80 & $\begin{array}{l}14,7 \text { (b) } \\
15,8 \\
16,2 \\
25,6 \\
11,9\end{array}$ & $\begin{array}{l}15,8 \\
16,0 \\
26,9 \\
11,3\end{array}$ & $\begin{array}{l}68,2 \text { (e) } \\
65,7 \\
66,8 \\
67,3 \\
67,6\end{array}$ & $\begin{array}{l}74,4 \text { (e) } \\
73,7 \\
75,2 \\
72,8 \\
75,1\end{array}$ \\
\hline $\begin{array}{l}\text { Europe du Sud } \\
\text { Albanie } \\
\text { Espagne } \\
\text { Grèce } \\
\text { Italie } \\
\text { Malte } \\
\text { Portugal } \\
\text { Yougoslavie }\end{array}$ & $\begin{array}{r}3208 \\
38889 \\
10033 \\
57541 \\
350 \\
10320 \\
23690\end{array}$ & $\begin{array}{c}79,7 \text { (b) } \\
410,1 \\
101,0 \\
555,7 \\
5,5 \text { (a) } \\
113,7 \\
335,9\end{array}$ & $\begin{array}{c}17,1 \text { (b) } \\
323,9 \\
92,0 \\
526,0 \\
2,7 \text { (a) } \\
96,2 \\
215,5\end{array}$ & $\begin{array}{l}25,9 \text { (b) } \\
10,5 \\
10,1 \\
9,7 \\
15,8 \text { (a) } \\
11,0 \\
14,2\end{array}$ & $\begin{array}{l}5,6(b) \\
8,3 \\
9,2 \\
9,1 \\
7,9(a) \\
9,3 \\
9,1\end{array}$ & $\begin{array}{l}3,16 \text { (b) } \\
1,38 \\
1,52 \\
1,33 \\
2,15 \text { (a) } \\
1,53 \\
1,98\end{array}$ & $\begin{array}{l}1,30 \\
1,50 \\
1,29\end{array}$ & $\begin{array}{l}28,2 \text { (b) } \\
10,0 \\
11,0 \\
9,3 \\
7,9 \\
14,2 \\
24,8\end{array}$ & $\begin{array}{r}8,3 \\
9,9 \\
8,8 \\
12,2 \\
23,7\end{array}$ & $\begin{array}{l}68,5 \\
73,1 \text { (e) } \\
72,6 \text { (e) } \\
72,6 \\
72,5 \\
70,7 \\
68,6\end{array}$ & $\begin{array}{l}73,9 \\
79,0 \text { (e) } \\
77,6 \text { (e) } \\
79,2 \\
77,0 \\
77,5 \\
73,8\end{array}$ \\
\hline $\begin{array}{l}\text { Europe des Douze } \\
\text { (y compris RDA) }\end{array}$ & $\begin{array}{l}326190 \\
342745\end{array}$ & $\begin{array}{l}3832 \\
4031\end{array}$ & $\begin{array}{l}3247 \\
3453\end{array}$ & $\begin{array}{l}11,7 \\
11,8\end{array}$ & $\begin{array}{l}10,0 \\
10,1\end{array}$ & $\begin{array}{r}1,60 \\
-\end{array}$ & 1,58 & $\begin{array}{r}8,5 \\
-\end{array}$ & $\begin{array}{l}8,2 \\
-\end{array}$ & $\begin{array}{r}72,0 \\
-\end{array}$ & $\begin{array}{r}78,6 \\
-\end{array}$ \\
\hline $\begin{array}{l}\text { États-Unis } \\
\text { Union soviétique } \\
\text { Japon }\end{array}$ & $\begin{array}{l}248870 \\
286717 \text { (1) } \\
123116\end{array}$ & $\begin{array}{l}4021,0 \\
5381,0 \text { (a) } \\
1269,3\end{array}$ & $\begin{array}{l}2155,0 \\
2889,0 \text { (a) } \\
794,0\end{array}$ & $\begin{array}{l}16,2 \\
18,8 \text { (a) } \\
10,1\end{array}$ & $\begin{array}{l}8,7 \\
10,1 \text { (a) } \\
6,4\end{array}$ & $\begin{array}{l}1,77 \\
2,53(b) \\
1,70(c)\end{array}$ & & $\begin{array}{r}9,9 \\
24,7 \\
4,8\end{array}$ & 9,7 & $\begin{array}{l}71,3 \\
65,0 \\
75,6\end{array}$ & $\begin{array}{l}78,3 \\
73,8 \\
81,4\end{array}$ \\
\hline $\begin{array}{l}\text { Canada } \\
\text { Australie } \\
\text { Nouvelle-Zélande }\end{array}$ & $\begin{array}{r}26250 \\
16810 \\
3310\end{array}$ & $\begin{array}{c}375,7 \text { (a) } \\
246,2 \text { (a) } \\
58,1\end{array}$ & $\begin{array}{c}189,1 \text { (a) } \\
119,9 \text { (a) } \\
27,0\end{array}$ & $\begin{array}{l}14,5 \text { (a) } \\
14,9 \text { (a) } \\
17,5\end{array}$ & $\begin{array}{l}7,3 \text { (a) } \\
7,2(a) \\
8,2\end{array}$ & $\begin{array}{l}1,66 \text { (b) } \\
1,87 \\
2,02 \text { (b) }\end{array}$ & & $\begin{array}{l}7,3(b) \\
8,7\end{array}$ & 10,2 & $\begin{array}{l}73,0 \text { (e) } \\
72,8 \\
71,0\end{array}$ & $\begin{array}{l}79,8(e) \\
79,1 \\
77,3\end{array}$ \\
\hline
\end{tabular}


$\mathrm{m} / \mathrm{s}$ a publié $\left(n^{\circ} 4\right.$, vol. 5, p. 264) une note sur la démographie de l'Europe des Douze, d'après des documents datant de 1986. L'Ined vient de fournir des données actualisées (1989) plus détaillées et étendues à toute l'Europe. Très denses, elles sont représentées dans le Tableau. La croissance, définie par la différence entre naissances et décès, hors flux migratoires, varie d'un pays à un autre, mais la moyenne ne dépasse pas 3 pour 1000 , contre 8 pour 1000 en URSS et 10 pour 1000 aux Etats-Unis (France : 4,2 pour 1000 ). Tous les pays gardent un solde positif, à l'exception des deux Allemagnes, encore séparées en 1989, et de la Hongrie. La fécondité la plus faible est désormais le fait de l'Italie et de l'Espagne, suivies de l'Allemagne. L'attention des démographes se porte sur la Suède pour deux raisons. Son indice de fécondité a remonté de 1,61 en 1983 à 2,02 en 1989. Cette augmentation résulte de la mise en place d'un calendrier plus tardif de la fécondité : les Suédoises ont leurs enfants plus tard sans en changer le nombre final ; ce phénomène se traduit par une baisse de l'indice conjoncturel de fécondité, suivie d'une remontée. Le modèle suédois est intéressant car il pourrait être reproduit par plusieurs autres pays. Par ailleurs, la nuptialité y a fait un bond surprenant, le nombre de mariages passant de 44000 en 1988 à 108000 en 1989 dont 64000 en décembre. Il ne s'agit toutefois pas d'une flambée amoureuse, mais des conséquences d'une loi excluant du bénéfice de la pension de réversion les femmes vivant en couple sans être mariées lorsqu'elles n'ont pas eu d'enfant...

[Monnier A. Population et Sociétés (Institut national d'études démographiques, Ined), octobre 1990, n 250 .] 